\section{The architecture of an excitatory synapse}

John J. E. Chua1, Stefan Kindler², Janina Boyken ${ }^{1}$ and Reinhard Jahn ${ }^{1, *}$

${ }^{1}$ Department of Neurobiology, Max-Planck-Institute for Biophysical Chemistry, D-37077 Göttingen, Germany

${ }^{2}$ Institute for Human Genetics, University Medical Center Hamburg-Eppendorf, D-20246 Hamburg,

Germany

*Author for correspondence (rjahn@gwdg.de)

Journal of Cell Science 123, 819-823

(c) 2010. Published by The Company of Biologists Ltd doi:10.1242/jcs.052696

The functioning of excitatory synapses in the mammalian brain is governed by macromolecular complexes that are held together by protein-protein, protein-lipid and lipid-lipid interactions. On the presynaptic side, neurotransmitter (NT)-filled synaptic vesicles
(SVs) are recruited to specialized release sites termed active zones. Glutamate is the major excitatory NT. It is released from presynaptic boutons, diffuses across the synaptic cleft and binds to postsynaptic NT receptors that alter the membrane potential and trigger signal transduction cascades. Action potentials arriving at presynaptic boutons trigger exocytosis and the retrieval of SV components from presynaptic membranes after membrane fusion (Jin and Garner, 2008; Schoch and Gundelfinger, 2006; Sudhof, 2004). On the postsynaptic side, multiprotein complexes that make up a region known as the postsynaptic density (PSD) mediate clustering of receptors and cell-adhesion molecules (CAMs) and orchestrate the coupling of diverse signaling components (Kim and Sheng, 2004). It has emerged that the loss or dysregulation of many synaptic proteins is a cause of a variety of neurological diseases. In this article, we describe the steps involved in synaptic transmission at excitatory central nervous system synapses and give an overview of the proteins governing these steps. To assist in orientation, the stages of the synaptic vesicle recycling pathway are numbered in the accompanying poster and are referred to in sequence below.

\section{Holding synapses together - the role of CAMs}

Pre- and postsynaptic membranes are held together by trans-synaptic interactions between CAMs. Major groups of synaptic CAMs include members of the immunoglobulin (Ig) family of adhesion molecules, neurexins and neuroligins, and ephrins and ephrin (Eph) receptors. Cadherins and synaptic cell-adhesion molecules (SynCAMs) (also referred to as nectin-like molecules) are single-pass transmembrane proteins that contain extracellular Ig domains (Biederer et al., 2002; Shapiro et al., 2007). Cadherins maintain a tight association between

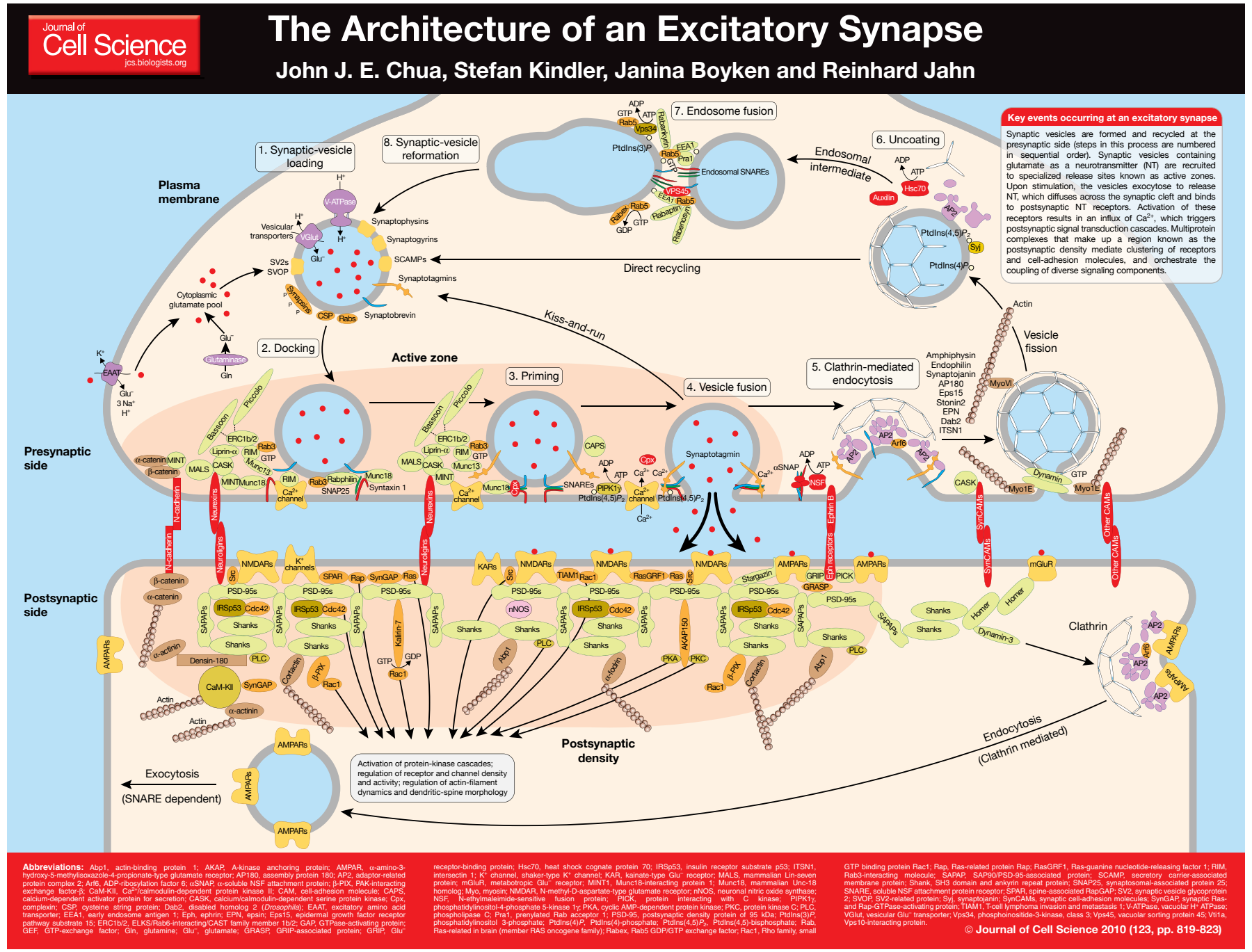

(See poster insert) 
pre- and post-synaptic compartments through $\mathrm{Ca}^{2+}$-dependent homophilic interactions. By contrast, SynCAMs preferentially form heterophilic $\mathrm{Ca}^{2+}$-independent connections (Fogel et al., 2007). Interactions between neurexins and neuroligins constitute another type of trans-synaptic linkage. Neurexins, which localize to presynaptic membranes, bind to an extracellular esterase-like domain that is present on postsynaptic neuroligins (Dalva et al., 2007). In addition to stabilizing synaptic contacts, interactions between Eph receptor tyrosine kinases and ephrins regulate processes such as axon outgrowth and pathfinding, and control the development of the neuronal architecture (Lai and Ip, 2009).

Many CAMs also bind to cytoplasmic scaffold proteins and regulate the assembly and function of supramolecular complexes. For example, binding of neurexins through the calcium/calmodulin-dependent serine protein kinase (CASK) to mammalian Lin-seven protein (MALS, also known as Veli), liprin- $\alpha$ and Munc18-interacting protein 1 (MINT1) regulates synaptic transmission (Atasoy et al., 2007; Olsen et al., 2005). Similarly, neuroligins bind members of the postsynaptic density protein of $95 \mathrm{kDa}$ (PSD-95) family, which are major regulators of postsynaptic signaling (Craig and Kang, 2007; Kim and Sheng, 2004).

\section{Presynaptic components - initiating the information transfer}

Stage 1: Synaptic vesicles

Synaptic vesicles (SVs) represent the storage organelle for NTs and are responsible for quantal release of NT packets of defined size (Bonanomi et al., 2006). Despite measuring only $40 \mathrm{~nm}$ in diameter, SVs are densely packed with an array of proteins (Takamori et al., 2006). At least nine classes of transmembrane proteins are specifically localized to SVs (Sudhof, 2004). These proteins are involved in NT loading and storage and in membrane trafficking, but the precise function is known for only a few of them. NT loading requires vesicular glutamate transporters (VGluts) and the vacuolar $\mathrm{H}^{+}$ ATPase (V-ATPase), which generates an electrochemical proton gradient across the SV membrane to drive NT uptake. Trafficking proteins include synaptobrevin [also known as vesicle-associated membrane protein (VAMP)] and synaptotagmin (see below). In addition, SVs include a heterogeneous group of proteins that contain four transmembrane domains [such as synaptophysin, synaptogyrin and secretory carrier-associated membrane proteins (SCAMPs)] (Abraham et al., 2006), as well as the proteins synaptic vesicle glycoprotein 2 (SV2) and SV2-related protein (SVOP), which resemble transporters, but are proposed to be involved in trafficking.

Membrane-associated SV proteins include synapsins and cysteine string protein (CSP). Synapsins were first identified as major synaptic phosphoproteins that are multiply phosphorylated by an array of protein kinases and they appear to regulate the availability of vesicles, although the molecular mechanisms involved are unclear (Fdez and Hilfiker, 2006). CSP is a member of the DnaJ family of cochaperones, which contain a string of 14 cysteine residues that is heavily palmitoylated and confers SV association. CSP, together with the uncoating ATPase heat shock cognate protein 70 (Hsc70) and small glutamine-rich tetratricopeptide-containing protein (SGT), functions as a molecular chaperone to salvage damaged components of the presynaptic release machinery (Fernandez-Chacon et al., 2004; Schmitz et al., 2006; Tobaben et al., 2001).

\section{Stage 2: Docking}

Morphologically, the close positioning of SVs to the presynaptic membrane is defined as docking (Verhage and Sorensen, 2008). Only a subset of $\mathrm{SVs}$ is recruited to sites of NT release (active zones). In electron microscopy images, these are discernable as electron-dense structures. Several classes of proteins are implicated in SV docking. For instance, a trimeric complex consisting of mammalian Unc-13 homolog (Munc13), Rab3 and Rab3-interacting molecule (RIM) has been postulated to recruit SVs to the presynaptic membrane (Dulubova et al., 2005). In addition, a presynaptic scaffold is organized around the docked vesicles and modulates NT release (Schoch and Gundelfinger, 2006). This supramolecular complex includes large multidomain proteins such as Bassoon, Piccolo, ELKS/Rab6-interacting/CAST family members (ERCs), liprin- $\alpha$, MINT1 (Rogelj et al., 2006), MALS (Olsen et al., 2006) and CASK (Hsueh, 2006). Together, these proteins form the building blocks of the active zone.

\section{Stage 3: Priming}

Priming comprises ATP-dependent reactions that render docked SVs competent to fuse with the plasma membrane when SV exocytosis is triggered by $\mathrm{Ca}^{2+}$ (Verhage and Sorensen, 2008). Priming steps include synthesis of phosphatidylinositol (4,5)-bisphosphate [PtdIns $\left.(4,5) P_{2}\right]$ by phosphatidylinositol-4phosphate 5-kinase $1 \gamma$ (PIPK1 $\gamma$ ) and disassembly of assembled soluble NSF attachment protein receptor (SNARE) complexes by the AAA+-ATPase Nethylmaleimide-sensitive fusion protein (NSF) and its co-factor $\alpha$-soluble NSF attachment protein $(\alpha \mathrm{SNAP})$.
Munc13 and RIM are also implicated in vesicle priming but act through ATPindependent mechanisms (Rizo and Rosenmund, 2008). A Munc13-dependent conformational change that converts syntaxin 1 from a closed to an open conformation is thought to have a role in priming reactions. RIM interacts with Munc13 and, although these proteins appear to act through a common pathway during vesicle priming, the details of this pathway are poorly understood.

\section{Stage 4: Fusion}

Arrival of an action potential at the presynapse triggers the opening of voltage-gated $\mathrm{Ca}^{2+}$ channels of the $\mathrm{N}$ or $\mathrm{P} / \mathrm{Q}$ type, followed by an influx of $\mathrm{Ca}^{2+}$ into the presynaptic bouton (Catterall and Few, 2008; Evans and Zamponi, 2006). Clustering of $\mathrm{Ca}^{2+}$ channels at vesiclerelease sites results in very high (but transient) local $\mathrm{Ca}^{2+}$ concentrations that are instrumental for fast exocytosis of SVs.

After entry into the presynaptic terminal, $\mathrm{Ca}^{2+}$ binds to synaptotagmin, an SV protein that functions as the $\mathrm{Ca}^{2+}$ sensor for fast $\mathrm{Ca}^{2+}$ triggered exocytosis. Synaptotagmin contains two $\mathrm{C}_{2}$ domains that mediate $\mathrm{Ca}^{2+}$-dependent binding to both membrane lipids and the SNARE proteins. The SNAREs form the core machinery for membrane fusion and include synaptobrevin located on the SV, and syntaxin 1 and synaptosomal-associated protein 25 (SNAP25) located on the presynaptic membrane (Jahn and Scheller, 2006). Before fusion, SNAREs initiate trans complexes that bridge the membranes. Fusion occurs when trans complexes assemble in a zipper-like manner towards the membrane anchors; the energy that is released during this assembly is thought to overcome the energy barrier required for fusion. A small protein, termed complexin (Cpx), binds to the surface of assembled SNARE complexes. Cpx probably 'optimizes' the partially assembled SNAREs for $\mathrm{Ca}^{2+}$ triggered exocytosis, and it has been suggested that it is displaced by synaptotagmin upon $\mathrm{Ca}^{2+}$ influx, triggering completion of SNARE zippering (Brose, 2008). Released NT diffuses across the synaptic cleft and binds to ionotropic receptors [N-methyl-D-aspartate receptors (NMDARs) and $\alpha$-amino-3-hydroxy-5methylisoxazole-4-propionate-type glutamate receptors (AMPARs)], as well as metabotropic glutamate receptors (mGluRs and KARs) and triggers postsynaptic receptor signaling cascades (see below for details).

\section{Stages 5-7: Endocytosis and recycling}

Synapses possess highly efficient mechanisms for retrieving SVs from the plasma membrane of the presynaptic terminal after exocytosis. Fast 
regeneration of functional SVs is a prerequisite for synapses to function during prolonged activity. Exocytosis appears to use two alternative pathways: clathrin-mediated endocytosis (CME), which is well established by numerous lines of evidence, and the more controversial 'kiss-and-run' pathway, which involves direct retrieval of a vesicle at the site of fusion (Rizzoli and Jahn, 2007). In contrast to the CME pathway, the molecular basis for the kiss-and-run pathway is unclear.

CME initiation (Stage 5) begins with the binding of adaptor proteins to vesicular membrane proteins (e.g. VGlut1 and synaptotagmin) and requires the presence of PtdIns $(4,5) P_{2}$, which is exclusively localized at the plasma membrane (coincidence detection) (Dittman and Ryan, 2009; Jung et al., 2007; Ungewickell and Hinrichsen, 2007). Adaptor proteins are either tetrameric [e.g. adaptorrelated protein complex 2 (AP2)] or monomeric (e.g. stonin). Cargo-bound AP2 stimulates PIPK1 $\gamma$, which increases local PtdIns(4,5) $P_{2}$ concentration, thereby facilitating recruitment of more adaptors that, in turn, recruit clathrin to assemble the clathrin coat. Subsequent invagination of the membrane is probably mediated by the coordinate actions of clathrin and proteins of the epsin N-terminal homology (ENTH) family [e.g. epsin (EPN)], BAR family (e.g. amphiphysin and endophilin) and EFC/F-BAR family. Eventually, dynamin assembles at the neck of the nascent vesicle and then constricts it through a GTP-dependent reaction, which contributes to membrane fission. The actin motors myosin-VI (plus-end directed) and myosin-1E (minus-end directed) bind Dab2 and PtdIns $(4,5) P_{2}$, and dynamin and synaptojanin (Syj), respectively, and might generate opposing forces that induce severing of the neck and free the vesicle into the cell interior (Ungewickell and Hinrichsen, 2007).

Disassembly of the clathrin coat (Stage 6) is initiated by several independent events, such as dephosphorylation of $\operatorname{PtdIns}(4,5) P_{2}$ to form PtdIns (4)-phosphate $[\operatorname{PtdIns}(4) P]$ by the phosphatase Syj or GTP cleavage by ADP ribosylation factor 1 (Arf1). PtdIns(4) $P$ might then recruit auxilin, which, together with $\mathrm{Hsc} 70$, removes the clathrin coat.

The fate of the endocytosed vesicle after uncoating is unclear (Bonanomi et al., 2006; Sudhof, 2004). One possibility is that these vesicles directly mature into functional SVs that are reloaded with NT and become competent for exocytosis. Alternatively, they might fuse with an intermediate endosomal compartment (Stage 7), thus allowing for sorting before budding of new SVs (Stage 8). The repertoire of proteins involved in endocytotic docking and fusion has been clarified recently using in vitro reconstitution and shown to include Rab5 and its effectors early endosome antigen 1 (EEA1), prenylated Rab acceptor 1 (Pra1), the PtdIns 3-phosphate $[\operatorname{PtdIns}(3) P]$ kinase Vps34, rabankyrin, the Sec1/Munc18 protein vacuolar sorting protein 45 (Vps45), rabaptin, rabenosyn, Rab5 GDP/GTP exchange factor (rabex), and the endosomal SNAREs syntaxin 13, syntaxin 6, Vps10-interacting protein (Vtila) and VAMP4 (Ohya et al., 2009).

\section{Information processing at the postsynaptic density}

Clustering of postsynaptic proteins receptor organization

The postsynaptic element of most excitatory synapses consists of a mushroom-like protrusion emanating from a dendrite, known as a dendritic spine (Newpher and Ehlers, 2008; Sheng and Hoogenraad, 2007; Tada and Sheng, 2006). In spine heads, the protein network of the PSD exactly aligns with the active zone (Feng and Zhang, 2009; Newpher and Ehlers, 2008; Schoch and Gundelfinger, 2006; Sheng and Hoogenraad, 2007). The PSD serves first to cluster glutamate receptors and CAMs; second, to recruit signaling proteins; and third, to anchor these components to the microfilament cytoskeleton of the spine. These functions are enabled by scaffold proteins found in the core of the PSD, such as members of the PSD-95 [also referred to as synapse-associated protein of $90 \mathrm{kDa}$ (SAP90)], SAP90/PSD-95-associated protein [SAPAP; also referred to as guanylate kinase-associated protein (GKAP)] and $\mathrm{SH} 3$ domain and ankyrin repeat protein [Shank; also referred to as proline-rich synapse-associated protein (ProSAP)] families. In the following sections, members of these three families are referred to as PSD-95s, SAPAPs and Shanks, respectively. Shanks are assumed to function as key organizers of the PSD (Kreienkamp, 2008; Schoch and Gundelfinger, 2006). They interact both directly and indirectly with various glutamate receptors, CAMs and ion channels. Furthermore, Shanks recruit signaling components and establish links with the actinbased cytoskeleton below the PSD. Through SAPAPs, Shanks bind to PSD-95s, which bind to and cluster NMDARs and kainate-type glutamate receptors (KARs), neuroligins and Shaker-type $\mathrm{K}^{+}$channels (Garcia et al., 1998; Kim and Sheng, 2004; Schoch and Gundelfinger, 2006). Similarly, AMPARs interact with PSD-95s through Stargazin [also referred to as transmembrane AMPA receptor regulatory proteins (TARPs)] (Newpher and Ehlers, 2008), whereas the glutamate receptorbinding protein (GRIP) and protein interacting with C kinase (PICK) appear to form an additional link to Eph receptors (Calo et al.,
2006; Klein, 2009). Certain types of metabotropic glutamate receptors (mGluRs) and inositol trisphosphate receptors bind to Shanks through Homer, and several additional membrane proteins bind directly to Shanks (Newpher and Ehlers, 2008; Schoch and Gundelfinger, 2006).

\section{Anchoring the postsynaptic signaling machinery - the actin connection}

Shanks also have a central role in establishing links to the actin network of the spine (Kreienkamp, 2008; Schoch and Gundelfinger, 2006). They associate with the actin-binding proteins $\alpha$-fodrin, cortactin and actinbinding protein 1 (Abp1). Also, the Shank-binding partner densin-180 interacts, directly or indirectly [through $\mathrm{Ca}^{2+} /$ calmodulindependent protein kinase II (CaM-KII)], with the actin-binding protein $\alpha$-actinin (Quitsch et al., 2005; Robison et al., 2005; Walikonis et al., 2001). In addition to Shanks, the postsynaptic CAM N-cadherin also associates with actin filaments via $\alpha$ - and $\beta$-catenin (Tai et al., 2008).

\section{Postsynaptic signaling - signal relays}

Glutamate acts on both mGluRs and ionotropic glutamate receptors (iGluRs). mGluRs are G-protein-linked receptors that couple to various intracellular signal transduction pathways. iGluRs are ligand-gated ion channels that are subdivided into NMDARs, AMPARs and KARs. Glutamate binding to AMPARs opens the ion channel and induces fast depolarization of the postsynaptic membrane, preferentially through the influx of $\mathrm{Na}^{+}$ions. By contrast, agonist-induced opening of NMDARs requires co-activation by glycine. Furthermore, NMDARs are blocked by extracellular $\mathrm{Mg}^{2+}$ at resting membrane potentials. Membrane depolarization relieves this block, enabling agonist-gated channel opening and $\mathrm{Ca}^{2+}$ influx into the spine. Intracellular $\mathrm{Ca}^{2+}$ binds to calmodulin (CaM) and activates different enzymes, including CaM-KII, adenylate cyclases AC1 and AC8, phosphodiesterase 1 (PDE1), neuronal nitric oxide synthase (nNOS), calcineurin and the Ras-guanine nucleotide-releasing factor 1 (RasGRF1), all of which compete for the limited amounts of $\mathrm{Ca}^{2+}$-CaM (Kennedy et al., 2005). AC1 and AC8, as well as PDE1, regulate postsynaptic cyclic AMP (cAMP) levels and thereby control local cAMPdependent protein kinase (PKA) activity. PKA and protein kinase $\mathrm{C}(\mathrm{PKC})$ directly associate with the A-kinase anchoring protein (AKAP79/150), which interacts with PSD-95s and consequently recruits both kinases into NMDAR complexes. Finally, phospholipase $C \beta$ 
(PLC $\beta$ ) couples to mGluRs via Shanks and Homer, which stimulate PLC activity (Hwang et al., 2005).

Scaffold proteins also recruit GTP-exchange factors (GEFs) and GTPase-activating proteins (GAPs), which control the GTPase activity of small GTPases and thereby regulate actin dynamics (Feng and Zhang, 2009; Kennedy et al., 2005; Tada and Sheng, 2006). Postsynaptic recruitment of the spine-associated RapGAP (SPAR) and synaptic Ras- and RapGTPase-activating protein (SynGAP) occurs by their interaction with various scaffold proteins (Kennedy et al., 2005; Kim et al., 1998; Pak et al., 2001; Wendholt et al., 2006). Similarly, Shanks bind to the GEF $\beta$-PIX, which activates Rac1 and Cdc42 and stimulates the formation of cellular protrusions (Park et al., 2003), whereas PSD-95s recruit kalirin-7, another Rac1 GEF (Sommer and Budreck, 2009). GRIP associates with the GRIP-associated protein (GRASP), a GEF, to promote Ras activity (Ye et al., 2000). In addition, NMDAR-associated GEFs RasGRF1 and T-cell lymphoma invasion and metastasis 1 (TIAM1) are activated by $\mathrm{Ca}^{2+}$ influx. Binding of $\mathrm{Ca}^{2+}$-CAM activates RasGRF1, which stimulates Ras. Ras then binds TIAM1 and allows it to activate Rac. Finally, direct binding of insulin receptor substrate p53 [IRSp53, also known as brain-specific angiogenesis inhibitor 1-associated protein 2 (BAIAP2)], an effector that acts downstream of active Rac 1 and $\mathrm{Cdc} 42$, to Shanks abrogates its effects on the actin cytoskeleton (Sawallisch et al., 2009).

\section{Synaptic plasticity - the dynamic synapse}

Whereas the number of NMDARs per synapse is quite stable at about 20, the number of AMPARs varies markedly, ranging from about 5 to 200 (Feng and Zhang, 2009; Newpher and Ehlers, 2008). The density of surface AMPARs is, at least in part, regulated by exocytic insertion and endocytotic removal. It is currently unclear whether neurons and spines possess dedicated sites of AMPAR exocytosis. NMDAR-mediated activation of CaM-KII and Ras is known to trigger AMPAR insertion into the postsynaptic membrane (Kennedy et al., 2005). To increase AMPAR levels, complexes consisting of various scaffold proteins (such as Stargazin and PSD-95s) might need to be assembled to provide 'slots' that trap AMPARs (Kessels and Malinow, 2009). The availability of these slots appears to be regulated by phosphorylation events. Furthermore, membrane insertion of AMPARs that have distinct subunit compositions seems to require different sets of scaffold proteins (Newpher and Ehlers, 2008).

At spines, CME of AMPARs occurs at endocytotic zones, which are located laterally to the PSD (Newpher and Ehlers, 2008). Molecular coupling of both sites occurs through dynamin 3 and Homer. $\mathrm{Ca}^{2+}$-dependent activation of Rab5 stimulates the formation of endocytotic vesicles, which are then delivered to early endosomes. Activity-dependent removal of AMPARs from synapses also involves scaffold proteins, such as PICK and GRIP, and subunit-specific phosphorylation and dephosphorylation events (Kessels and Malinow, 2009). Additionally, presynaptic forms of plasticity that are mediated, for example by RIM, also exist in certain regions of the brain (Garcia-Junco-Clemente et al., 2005; Kaeser and Sudhof, 2005).

\section{Perspectives}

Over the past two decades, we have witnessed tremendous progress in our understanding of the molecular components involved in signal transduction at excitatory synapses of the mammalian central nervous system. In particular, the dynamic assembly of synaptic proteins into macromolecular complexes that orchestrate individual signaling events has become evident. Despite this progress, however, we are only now beginning to understand how these assembly and signaling mechanisms act together to allow higher brain functions, such as learning and memory, which are thought to require exquisite fine-tuning between synaptic plasticity and long-term stability. There is growing evidence that the functional loss or dysregulation of single synaptic molecules is associated with various neurological diseases. For example, mutations in the genes encoding neurexin 1, neuroligin 3, neuroligin 4 and Shank 3 have recently been shown to be associated with an increased susceptibility to autism (Bourgeron, 2009). A better understanding of the complex mechanistic regulations that underlie cognitive processes is urgently needed in order to provide molecular targets for drug intervention and treatment of human neurological disorders.

The authors are indebted to Erwin Neher and Oliver Schlüter (Göttingen) and to Thomas C. Südhof (Stanford) for critical comments. The research leading to these results has received funding from the European Union Sixth and Seventh Framework Programmes under grant agreement no. LSHM-CT-2005-019055 ('EUSynapse') and no. HEALTH-F2-2009-241498 ('EUROSPIN'), respectively. Financial support from the Deutsche Forschungsgemeinschaft (Ki488/2-6 and KR 1321/4-1 to S.K.), Thyssen-Stiftung (Az. 10.05.2.185 to S.K.) and The National Ataxia Foundation (to S.K.) is acknowledged.

\section{References}

Abraham, C., Hutter, H., Palfreyman, M. T. Spatkowski, G., Weimer, R. M., Windoffer, R., Jorgensen, E. M. and Leube, R. E. (2006). Synaptic tetraspan vesicle membrane proteins are conserved but not needed for synaptogenesis and neuronal function in
Caenorhabditis elegans. Proc. Natl. Acad. Sci. USA 103, 8227-8232.

Atasoy, D., Schoch, S., Ho, A., Nadasy, K. A., Liu, X., Zhang, W., Mukherjee, K., Nosyreva, E. D., FernandezChacon, R., Missler, M. et al. (2007). Deletion of CASK in mice is lethal and impairs synaptic function. Proc. Natl. Acad. Sci. USA 104, 2525-2530.

Biederer, T., Sara, Y., Mozhayeva, M., Atasoy, D., Liu, X., Kavalali, E. T. and Sudhof, T. C. (2002). SynCAM, a synaptic adhesion molecule that drives synapse assembly. Science 297, 1525-1531.

Bonanomi, D., Benfenati, F. and Valtorta, F. (2006). Protein sorting in the synaptic vesicle life cycle. Prog. Neurobiol. 80, 177-217.

Bourgeron, T. (2009). A synaptic trek to autism. Curr. Opin. Neurobiol. 19, 231-234.

Brose, N. (2008). For better or for worse: complexins regulate SNARE function and vesicle fusion. Traffic $\mathbf{9}$, 1403-1413.

Calo, L., Cinque, C., Patane, M., Schillaci, D., Battaglia, G., Melchiorri, D., Nicoletti, F. and Bruno, V. (2006). Interaction between ephrins/Eph receptors and excitatory amino acid receptors: possible relevance in the regulation of synaptic plasticity and in the pathophysiology of neuronal degeneration. J. Neurochem. 98, 1-10.

Catterall, W. A. and Few, A. P. (2008). Calcium channel regulation and presynaptic plasticity. Neuron 59, 882-901. Craig, A. M. and Kang, Y. (2007). Neurexin-neuroligin signaling in synapse development. Curr. Opin. Neurobiol. 17, 43-52.

Dalva, M. B., McClelland, A. C. and Kayser, M. S. (2007). Cell adhesion molecules: signalling functions at the synapse. Nat. Rev. Neurosci. 8, 206-220.

Dittman, J. and Ryan, T. A. (2009). Molecular Circuitry of Endocytosis at Nerve Terminals. Annu. Rev. Cell Dev. Biol. 25, 133-160.

Dulubova, I., Lou, X., Lu, J., Huryeva, I., Alam, A., Schneggenburger, R., Sudhof, T. C. and Rizo, J. (2005). A Munc13/RIM/Rab3 tripartite complex: from priming to plasticity? EMBO J. 24, 2839-2850.

Evans, R. M. and Zamponi, G. W. (2006). Presynaptic $\mathrm{Ca}^{2+}$ channels-integration centers for neuronal signaling pathways. Trends Neurosci. 29, 617-624.

Fdez, E. and Hilfiker, S. (2006). Vesicle pools and synapsins: new insights into old enigmas. Brain Cell Biol. 35, 107-115.

Feng, W. and Zhang, M. (2009). Organization and dynamics of PDZ-domain-related supramodules in the postsynaptic density. Nat. Rev. Neurosci. 10, 87-99.

Fernandez-Chacon, R., Wolfel, M., Nishimune, H., Tabares, L., Schmitz, F., Castellano-Munoz, M., Rosenmund, C., Montesinos, M. L., Sanes, J. R., Schneggenburger, R. et al. (2004). The synaptic vesicle protein CSP alpha prevents presynaptic degeneration. Neuron 42, 237-251.

Fogel, A. I., Akins, M. R., Krupp, A. J., Stagi, M., Stein, V. and Biederer, T. (2007). SynCAMs organize synapses through heterophilic adhesion. J. Neurosci. 27, 1251612530 .

Garcia, E. P., Mehta, S., Blair, L. A., Wells, D. G., Shang, J., Fukushima, T., Fallon, J. R., Garner, C. C. and Marshall, J. (1998). SAP90 binds and clusters kainate receptors causing incomplete desensitization. Neuron 21, 727-739.

Garcia-Junco-Clemente, P., Linares-Clemente, P. and Fernandez-Chacon, R. (2005). Active zones for presynaptic plasticity in the brain. Mol. Psychiatry 10, 185200; image 131

Hsueh, Y. P. (2006). The role of the MAGUK protein CASK in neural development and synaptic function. Curr. Med. Chem. 13, 1915-1927.

Hwang, J. I., Kim, H. S., Lee, J. R., Kim, E., Ryu, S. H. and Suh, P. G. (2005). The interaction of phospholipase Cbeta3 with Shank2 regulates mGluR-mediated calcium signal. J. Biol. Chem. 280, 12467-12473.

Jahn, R. and Scheller, R. H. (2006). SNAREs-engines for membrane fusion. Nat. Rev. Mol. Cell Biol. 7, 631-643.

Jin, Y. and Garner, C. C. (2008). Molecular mechanisms of presynaptic differentiation. Annu. Rev. Cell Dev. Biol. 24, 237-262.

Jung, N., Wienisch, M., Gu, M., Rand, J. B., Muller, S. L., Krause, G., Jorgensen, E. M., Klingauf, J. and Haucke, V. (2007). Molecular basis of synaptic vesicle 
cargo recognition by the endocytic sorting adaptor stonin 2 . J. Cell Biol. 179, 1497-1510.

Kaeser, P. S. and Sudhof, T. C. (2005). RIM function in short- and long-term synaptic plasticity. Biochem. Soc. Trans. 33, 1345-1349.

Kennedy, M. B., Beale, H. C., Carlisle, H. J. and Washburn, L. R. (2005). Integration of biochemical signalling in spines. Nat. Rev. Neurosci. 6, 423-434.

Kessels, H. W. and Malinow, R. (2009). Synaptic AMPA receptor plasticity and behavior. Neuron 61, 340-350.

Kim, E. and Sheng, M. (2004). PDZ domain proteins of synapses. Nat. Rev. Neurosci. 5, 771-781.

Kim, J. H., Liao, D., Lau, L. F. and Huganir, R. L. (1998) SynGAP: a synaptic RasGAP that associates with the PSD95/SAP90 protein family. Neuron 20, 683-691.

Klein, R. (2009). Bidirectional modulation of synaptic functions by Eph/ephrin signaling. Nat. Neurosci. 12, 15-20. Kreienkamp, H. J. (2008). Scaffolding proteins at the postsynaptic density: shank as the architectural framework. Handb. Exp. Pharmacol. 186, 365-380.

Lai, K. O. and Ip, N. Y. (2009). Synapse development and plasticity: roles of ephrin/Eph receptor signaling. Curr. Opin. Neurobiol. 19, 275-283.

Newpher, T. M. and Ehlers, M. D. (2008). Glutamate receptor dynamics in dendritic microdomains. Neuron $\mathbf{5 8}$, 472-497.

Ohya, T., Miaczynska, M., Coskun, U., Lommer, B. Runge, A., Drechsel, D., Kalaidzidis, Y. and Zerial, M. (2009). Reconstitution of Rab- and SNARE-dependent membrane fusion by synthetic endosomes. Nature $\mathbf{4 5 9}$, 1091-1097.

Olsen, O., Moore, K. A., Fukata, M., Kazuta, T., Trinidad, J. C., Kauer, F. W., Streuli, M., Misawa, H., Burlingame, A. L., Nicoll, R. A. et al. (2005). Neurotransmitter release regulated by a MALS-liprin-alpha presynaptic complex. J. Cell Biol. 170, 1127-1134.

Olsen, O., Moore, K. A., Nicoll, R. A. and Bredt, D. S. (2006). Synaptic transmission regulated by a presynaptic MALS/Liprin-alpha protein complex. Curr. Opin. Cell Biol. 18, 223-227

Pak, D. T., Yang, S., Rudolph-Correia, S., Kim, E. and Sheng, M. (2001). Regulation of dendritic spine morphology by SPAR, a PSD-95-associated RapGAP Neuron 31, 289-303.

Park, E., Na, M., Choi, J., Kim, S., Lee, J. R., Yoon, J.,

Park, D., Sheng, M. and Kim, E. (2003). The Shank family of postsynaptic density proteins interacts with and promotes synaptic accumulation of the beta PIX guanine nucleotide exchange factor for Rac1 and Cdc42. J. Biol. Chem. 278, 19220-12929.

Quitsch, A., Berhorster, K., Liew, C. W., Richter, D. and Kreienkamp, H. J. (2005). Postsynaptic shank antagonizes dendrite branching induced by the leucine-rich repeat protein Densin-180. J. Neurosci. 25, 479-487.

Rizo, J. and Rosenmund, C. (2008). Synaptic vesicle fusion. Nat. Struct. Mol. Biol. 15, 665-674.

Rizzoli, S. O. and Jahn, R. (2007). Kiss-and-run, collapse and 'readily retrievable' vesicles. Traffic 8, 1137-1144.

Robison, A. J., Bass, M. A., Jiao, Y., MacMillan, L. B. Carmody, L. C., Bartlett, R. K. and Colbran, R. J. (2005). Multivalent interactions of calcium/calmodulindependent protein kinase II with the postsynaptic density proteins NR2B, densin-180, and alpha-actinin-2. J. Biol. Chem. 280, 35329-35336.

Rogelj, B., Mitchell, J. C., Miller, C. C. and McLoughlin, D. M. (2006). The X11/Mint family of adaptor proteins. Brain Res. Rev. 52, 305-315.

Sawallisch, C., Berhorster, K., Disanza, A., Mantoani, S. Kintscher, M., Stoenica, L., Dityatev, A., Sieber, S., Kindler, S., Morellini, F. et al. (2009). The insulin receptor substrate of $53 \mathrm{kDa}$ (IRSp53) limits hippocampal synaptic plasticity. J. Biol. Chem. 284, 9225-9236.

Schmitz, F., Tabares, L., Khimich, D., Strenzke, N., de la Villa-Polo, P., Castellano-Munoz, M., Bulankina, A. Moser, T., Fernandez-Chacon, R. and Sudhof, T. C. (2006). CSPalpha-deficiency causes massive and rapid photoreceptor degeneration. Proc. Natl. Acad. Sci. USA 103 2926-2931.

Schoch, S. and Gundelfinger, E. D. (2006). Molecular organization of the presynaptic active zone. Cell Tissue Res. 326, 379-391.

Shapiro, L., Love, J. and Colman, D. R. (2007). Adhesion molecules in the nervous system: structural insights into function and diversity. Annu. Rev. Neurosci. 30, 451-474.

Sheng, M. and Hoogenraad, C. C. (2007). The postsynaptic architecture of excitatory synapses: a more quantitative view. Annu. Rev. Biochem. 76, 823-847.

Sommer, J. E. and Budreck, E. C. (2009). Kalirin-7: linking spine plasticity and behavior. J. Neurosci. 29, 5367 5369

Sudhof, T. C. (2004). The synaptic vesicle cycle. Annu. Rev

Neurosci. 27, 509-547.
Tada, T. and Sheng, M. (2006). Molecular mechanisms of dendritic spine morphogenesis. Curr. Opin. Neurobiol. 16, 95-101

Tai, C. Y., Kim, S. A. and Schuman, E. M. (2008). Cadherins and synaptic plasticity. Curr. Opin. Cell Biol. 20, 567-575.

Takamori, S., Holt, M., Stenius, K., Lemke, E. A., Gronborg, M., Riedel, D., Urlaub, H., Schenck, S., Brugger, B., Ringler, P. et al. (2006). Molecular anatomy of a trafficking organelle. Cell 127, 831-846.

Tobaben, S., Thakur, P., Fernandez-Chacon, R., Sudhof, T. C., Rettig, J. and Stahl, B. (2001). A trimeric protein complex functions as a synaptic chaperone machine. Neuron 31, 987-999.

Ungewickell, E. J. and Hinrichsen, L. (2007). Endocytosis: clathrin-mediated membrane budding. Curr. Opin. Cell Biol. 19, 417-425.

Verhage, M. and Sorensen, J. B. (2008). Vesicle docking in regulated exocytosis. Traffic 9, 1414-1424.

Walikonis, R. S., Oguni, A., Khorosheva, E. M., Jeng, C. J., Asuncion, F. J. and Kennedy, M. B. (2001). Densin180 forms a ternary complex with the (alpha)-subunit of $\mathrm{Ca}^{2+} /$ calmodulin-dependent protein kinase II and (alpha)actinin. J. Neurosci. 21, 423-433.

Wendholt, D., Spilker, C., Schmitt, A., Dolnik, A., Smalla, K. H., Proepper, C., Bockmann, J., Sobue, K., Gundelfinger, E. D., Kreutz, M. R. et al. (2006). ProSAPinteracting protein 1 (ProSAPiP1), a novel protein of the postsynaptic density that links the spine-associated RapGap (SPAR) to the scaffolding protein ProSAP2/Shank3. J. Biol. Chem. 281, 13805-13816.

Ye, B., Liao, D., Zhang, X., Zhang, P., Dong, H. and Huganir, R. L. (2000). GRASP-1: a neuronal RasGEF associated with the AMPA receptor/GRIP complex. Neuron 26, 603-617.

\section{Cell Science at a Glance on the Web}

Electronic copies of the poster insert are available in the online version of this article at jcs.biologists.org. The JPEG images can be downloaded for printing or used as slides.

\section{Commentaries and Cell Science at a Glance}

JCS Commentaries highlight and critically discuss recent and exciting findings that will interest those who work in cell biology, molecular biology, genetics and related disciplines, whereas Cell Science at a Glance poster articles are short primers that act as an introduction to an area of cell biology, and include a large poster and accompanying text.

Both of these article types, designed to appeal to specialists and nonspecialists alike, are commissioned from leading figures in the field and are subject to rigorous peer-review and in-house editorial appraisal. Each issue of the journal usually contains at least one of each article type. JCS thus provides readers with more than 50 topical pieces each year, which cover the complete spectrum of cell science. The following are just some of the areas that will be covered in JCS over the coming months:

\section{Cell Science at a Glance}

The unfolded protein response and cell fate at a glance Feroz Papa

Argonaute proteins at a glance Gunter Meister

The nuclear envelope: a long view Kathy Wilson

Switches of the integrin adhesome Benny Geiger

\section{Commentaries}

Cellular functions of FAK kinases Michael Schaller

Prion-like disorders James Shorter

siRNA delivery and endosome escape Derek Dykxhoorn

TIRF microscopy for the cell biologist Josh Rappoport

Although we discourage the submission of unsolicited Commentaries and Cell Science at a Glance poster articles to the journal, ideas for future articles in the form of a short proposal and some key references - are welcome and should be sent by email to the Editorial Office (jcs@ biologists.com). 